China's move to higher-meat diet hits water security

SIR - Your Editorial 'A fresh approach to water' (Nature 452, 253 ; 2008) points out that the world's looming water crisis is driven by climate change, population growth and economic development. In China, changing food-consumption patterns are the main cause of the worsening water scarcity. If other developing countries follow China's trend towards protein-rich Western diets, the global water shortage will become still more severe.

In China, it takes 2,400-12,600 litres of water to produce a kilogram of meat, whereas a kilogram of cereal needs only 800-1,300 litres (J. Liu and $\mathrm{H}$. H. G. Savenije Hydrol. Earth Syst. Sci. 12, 887-898; 2008). The recent rise in meat consumption has pushed China's annual per capita water requirement for food production up by a factor of 3.4 from 255 cubic metres in 1961 to 860 cubic metres in 2003. Compared with China's population growth by a factor of 1.9 over the same period, this suggests that dietary change is making a high demand on water resources.

China's water requirement for food production is still well below that of many developed countries. The United States, for example, uses 1,820 cubic metres per capita per year. But the steady increase in the amount of meat in Chinese diets is worrying. Consumption already exceeds by $50 \%$ the optimal amount recommended by the Chinese Nutrition Society - although discrepancies between rural and urban areas and between eastern and western regions are significant. This diet shift may also have detrimental effects on the population's health, as in developed countries. In general, changes in food-consumption patterns are closely related to affluence, although they are influenced by food preferences as well. Raising public awareness about healthy eating habits could also help to mitigate water scarcity.

Junguo Liu and Hong Yang Swiss Federal Institute of Aquatic Science and Technology, Ueberlandstrasse 133 , PO Box 611, CH-8600, Dübendorf, Switzerland e-mail:water21water@yahoo.com H. H. G. Savenije Delft University of Technology, Department of Water Management, PO Box 5048, 2601 DA, Delft, The Netherlands, See Editorial, page 367

\section{In the wake of two retractions, a request for investigation}

SIR - Your Editorial 'Negative results' (Nature 453, 258; 2008) and News Feature 'Designer debacle' (Nature 453, 275-278; 2008), on the retraction of two papers from my laboratory and the events surrounding those retractions, have provided opportunity for misunderstanding and misinterpretation.

Regrettably, as with all human endeavours, mistakes can occur in scientific research. When a mistake is made, it should be admitted through retraction of the published paper. Such retractions should then lead to a process of impartial scientific enquiry and analysis, as well as introspection by the participants.

I have acknowledged, and will continue to acknowledge, my personal responsibility to the scientific community for these errors as well as my responsibility as a research supervisor to my students.

As my actions have been called into question, I have asked the Duke University Medical Center administration to hold a formal and impartial inquiry into these retractions and the events that have followed. My request has been granted by the university.

Homme W. Hellinga Duke University Medical Center, Durham, North Carolina 27710, USA e-mail: hwh@biochem.duke.edu

\section{Fusion needs a realistic cost assessment}

SIR - In your Editorial about the increasing expense of the ITER fusion reactor ('The price isn't right' Nature 453, 824; 2008), you suggest that scientists might be suspected of deliberately underquoting the price to help sell the project. Possibly. What then should one make of the projected costs of fusion energy outlined in the European Fusion Development Agency in its 2005 report (see http://tinyurl.com/5gvh5o)?

The report gives a projected electricity cost for a 1.5-gigawatt plant of conservative design of $€ 0.09$ (US\$0.14) per kilowatthour. This is rather high compared with, say, renewables; but it goes on to state (on the basis of untested conceptual designs with less conventional materials) that this cost would be reduced to $€ 0.05$ per kilowatt-hour "in a mature fusion industry". This figure is only a little higher than for conventional nuclear power plants. Moreover, it has been quoted by leaders in the fusion community (see C. LlewellynSmith and D. Ward, Nuclear Future 2, 93-100; 2006). Hidden in these projected costs is that both the $€ 0.09$ and $€ 0.05$ numbers have already been reduced by a factor of 0.65 to give the cost of 'a tenth of a kind' - that is, for the tenth reactor. The original cost estimate of nearly $€ 0.14$ per kilowatt-hour has been cleverly reduced by almost a factor of three. At a time when the economics of fusion energy needed some support, one cannot help admiring this approach.

As the costs of ITER come under further pressure on all sides and the huge technical problems become recognized, there is an urgent need for realistic and independent assessment of the costs of a practical fusion device, and even as to whether it is sensible for the programme to continue. Apart from the plasma conditions, what about the tritium breeding and reprocessing, the massive materials problems in a radiation-damage environment, the near-impossibility of maintenance and the difficulty of maintaining the integrity of superconducting magnets over long periods? The list of areas where heroic engineering is needed goes on and on.

As US physicist William Metz once said, "It sometimes seems necessary to suspend one's normal critical faculties not to find the problems of fusion overwhelming." The fusion story is like a snowball going downhill gathering mass and momentum - impossible to stop, and at the end there will be only a pool of water to show for all the effort.

J. H. Evans Abingdon, Oxfordshire, UK e-mail:jhevans@sky.com

\section{Fewer academics are not the answer to funding woes}

SIR — In his Correspondence 'Fewer academics could be the answer to insufficient grants' (Nature 453, 978; 2008), Andrew Doig suggests that the endemic problem of the rejection of highquality grant proposals could be solved by cutting the number of academic staff. This proposal could create a new problem.

The number of academic staff is generally related to the number of undergraduates. Cutting the number of academics would reduce the number of trained students produced, which would have a negative effect on the nation's health and wealth.

In this increasingly technological age, we need all the trained scientists we can muster to combat issues such as global warming. The way to prevent the rejection of high-quality grant proposals and to support research is to put a bit more money into the system.

Philip Strange School of Pharmacy, University of Reading, Reading, Berkshire RG6 6AJ, UK e-mail:p.g.strange@reading.ac.uk 